\title{
'Dearest beloved one, I need your assistance': the rhetoric of
}

\section{spam mail}

Aysha Iqbal Viswamohan, Charles Hadfield, and Jill Hadfield

\section{Introduction \\ Dearest beloved one, I need your assistance}

\begin{abstract}
Most of us receive spam or junk mail every day. While we are often tempted, on first impulse, to delete them, a close reading of these emails provides some interesting insights to those of us who deal with teaching and research in English language, particularly in the context of language and culture. This article will attempt to analyse the linguistic features and discourse strategies of spam emails, mail which is unsolicited and unwanted by the recipient. While the language of specific technical domains, such as emails or SMS messages has been the subject of academic analysis, junk mail has been a neglected field. Although there are several kinds of spam or junk emails, this article will focus on those which promise an inheritance from a benefactor from distant shores: the 'Dearly beloved' genre of spam emails, where an unknown sender sends a message to the receiver, pleading for kindness, mercy, or charity and promising monetary gain in recompense. A close reading of such spam mail can lead to interesting findings on the interdependent roles of language, culture, and technology.
\end{abstract}

\section{The texts}

\section{Email 1}

Dear Beloved In The Lord. Greetings in the name of Jesus Christ!

I am Dr Mrs Anna Williams Origin of I am married to Late Dr bona Williams a businessman in Ivory Coast

Recently, following my ill health, my Doctor told me that I may not last for the next eight months due to my cancer problem. he told me that in the next 2 months there is going to be a spread of this cancer to my bones and I will not live again, Having known my condition I decided to donate this fund to a Christian, Individual and Organization whom I know may need it and will utilize this money the way I am going to instruct herein, according to the desire of my late husband before his death.

While my late husband was alive he kept the sum of (US\$5.000.000.00) Five Million United States Dollar) DEPOSITED IN A SECURITY COMPANY HERE IN _ IN A TRUNK BOX. HE USED MY NAME AS NEXT OF KIN AND NOT THE BENEFICIARY DUE TO OUR POLITICAL STATUS AND THE NATURE OF DEPOSIT I CAN NOT SERVE AS THE BENEFICIARY MUST BE MY husband's BUSINESS PARTNER in ABROAD.

Presently, this money is still with the SECURITY COMPANY I want this fund to be used in liberation work Activities like, help to Pastors families, Orphanages, less privileged in the society and Christian schools, poor people in your amidst and 
up keeping of the Churches and for propagating the word of God and to endeavour that the house of God is maintained.

The Bible made us to understand that 'Blessed is the hand that giveth'. I took this decision because I don't have any child that will inherit this money and I want my husband's efforts to be used help humanity. I don't want a situation where this money will be used in an ungodly way. This is why I am taking this decision. I am not afraid of death hence I know where I am going. I know that I am going to be in the bosom of the Lord. Exodus 14 VS 14 says that 'the Lord will fight my case and I shall hold my peace'. I don't need any telephone communication in this regard because of my health hence the presences of my husband's relatives are around me always. I don't want them to know about this development because they are muslims. With God all things are possible.

As soon as I receive your reply I shall give you the contact of the finance SECURITY COMPANY in Abidjan. I will also issue you the documents that will prove you the present beneficiary of this fund. I want you to always pray for me because the lord is my shepherd. My happiness is that I lived a life of a worthy Christian. Whoever that wants to serve the Lord must serve him in spirit and Truth.

Please always be prayerful all through your life. Contact me any delay in your reply will give me room in sourcing another for this same purpose, Please assure me that you will act accordingly as I Stated herein. Hoping to receive your reply.

Remain blessed in the Lord.

Yours in Christ,

Dr Mrs Anna Williams

\section{Email 2}

Attn: Sir/Madam,

\section{PAYMENT NOTIFICATION OF YOUR FUNDS.}

Definitely, I am sure that the receipt of this email will be of utmost blessing to you. Firstly, I will like to introduce myself formally; I am Mr.

Prof. , The Executive Governor of The Central Bank of the secretary to

You are been officially contacted by me today because I was instructed to do so by my boss, kindly note that your Funds were Re-deposited into the 'Federal Suspense Accountl' of the CBN last week, because you did not forward your Claim as the Right beneficiary. The Central Bank of is the parent Bank of all commercial Banks here.

My boss the Governor, was visited in his office by some Gentlemen today, really these men were unexpected by him because their visit was impromptu. He had to ask them why they came to see him in person and they said that they were here to collect the Inheritance/contract funds Bill Sum of (US\$5.5,000,000:00) \$5.5 million which rightfully belongs to you, on your behalf. 
At this development He asked them who authorized them to come down to for the Collection of this Payment and they told him that you asked them to come and collect these Funds on your Behalf. In fact this was the biggest shock that this Bank has ever received so far because your Inheritance Funds is still in the ।'Federal Suspense Accountl' of CBN, yet you sent these men to come and collect this Funds on your behalf without notifying us.

We do not understand why you should send these men to come and Collect your Funds on your behalf. If actually you want them to help you collect your funds, you should have at least informed him officially as the Executive Governor of this Bank.

Note that they actually tendered some Vital Documents which proved that you actually sent them for the Collection of these Funds. Honestly, it really shocked him that you took such a decision without his consent. Below is list of the Documents which they tendered to this Bank today:

$\begin{array}{ll}1 & \text { LETTER OF ADMINISTRATION. } \\ 2 & \text { HIGH COURT INJUCTION. } \\ 3 & \text { ORDER TO RELEASE. }\end{array}$

Actually, these Documents which they tendered to this Noble Bank are a clear Proof that you sent them to Collect this Funds for you. Finally, He, Prof __ told them to come back tomorrow morning and they promised to come back. As the Governor of this Noble Bank, he was supposed to Release this Funds to them but he refused to do so because he wanted to clarify this from you first. KINDLY DO GET BACK TO ME WITH YOUR TELEPHONE NUMBER SO I CAN REACH YOU AS FAST AS POSSIBLE OK.

Due to the Nature of his job, he cannot afford to make any mistake in releasing these Funds to anyone except you whom is the Recognized Bonafide Beneficiary to these Funds.

Kindly clarify us on this issue before we make this Payment to these foreigners whom came on your behalf.

Yours Faithfully,

Mr.

Secretary.

TO THE GOVERNOR.

CENTRAL BANK OF

\section{Language notes}

The 'Dearly beloved' genre of spam emails is distinguished by a combination of elaborate and formal language together with emotive and dramatic rhetorical devices. At the same time, the emails exhibit a number of colloquialisms, syntactical, lexical, and punctuation errors and inappropriacies, which contrast oddly with the elevated style.

\section{Elaborate and formal style}

\section{Excessive use of formal discourse markers}

The emails have a high density of formal discourse markers, used to connect, but more often to introduce sentences: 
- Recently, following my ill health, my Doctor told me that I may not last for the next eight months.

- Having known my condition, I decided to donate this fund. n Presently, this money is still with the SECURITY COMPANY ...

- Definitely, I am sure that the receipt of this email will be of utmost blessing to you.

- Firstly, I will like to introduce myself formally ...

\section{Lengthy and complex sentence structure}

Sentences are very long with a complex structure containing many embedded clauses.

- Having known my condition I decided to donate this fund to a Christian, Individual and Organization whom I know may need it and will utilize this money the way I am going to instruct herein, according to the desire of my late husband before his death.

Sometimes the clauses are so embedded that it is difficult to disentangle them!

- HE USED MY NAME AS NEXT OF KIN AND NOT THE BENEFICIARY DUE TO OUR POLITICAL STATUS AND THE NATURE OF DEPOSIT I CAN NOT SERVE AS THE BENEFICIARY MUST BE MY husband's BUSINESS PARTNER in ABROAD.

\section{Elaborate greetings and politeness markers}

The emails use elaborate and deferential greetings and honorifics.

- Dear Beloved In The Lord. Greetings in the name of Jesus Christ!

- As the Governor of this Noble Bank.

\section{Formal business letter language}

The emails use language usually associated with formal business letters rather than the informality of emails.

- Kindly clarify us on this issue before we make this Payment to these foreigners whom came on your behalf.

- Please assure me that you will act accordingly as I Stated herein.

\section{Emotive and dramatic devices}

\section{Emotive language}

Language is often used to evoke an emotional response, frequently with reference to religious belief.

- I am not afraid of death hence I know where I am going. I know that I am going to be in the bosom of the Lord.

\section{Dramatic effect}

Capitals and italics are used to add drama and urgency.

- While my late husband was alive he kept the sum of ...DEPOSITED IN A SECURITY COMPANY HERE IN IN ATRUNK BOX.

- My boss the Governor, was visited in his office by some Gentlemen today, really these men were unexpected by him... 


\section{Colloquialisms}

There is frequently a descent from elevated and formal language, the written register, to colloquialisms, the language of speech, usually in order to convey a sense of immediacy and urgency.

- KI NDLY DO GET BACK TO ME WITH YOUR TELEPHONE NUMBER SO I CAN REACH YOU AS FAST AS POSSIBLE OK.

- Honestly, it really shocked him ...

\section{Grammatical, lexical, and punctuation errors and inappropriacies}

\section{Grammatical errors}

Much of the syntax is complex and correctly formed. Because of this, the errors sprinkled through the text appear intrusive and surprising.

- I don't have any child that will inherit this money ...

- the presences of my husband's relatives are around me always...

\section{Lexical errors and inappropriacies}

These fall into three main categories:

a Errors in collocation

- I will not live again...

- $\quad$ any delay in your reply will give me room in sourcing another...

b Errors in part of speech

- $\quad$ poor people in your amidst ...

c Stylistic inappropriacy

- $\quad$ these men were unexpected by him because their visit was impromptu.

\section{Punctuation errors}

Full stops and capital letters are frequently omitted.

- Contact me any delay in your reply will give me room in sourcing another for this same purpose ...

\section{Commentary}

This commentary will give a brief overview of the strategies deployed by spammers in the 'Dearly beloved' genre, followed by a stylistic analysis of how the very rhetorical features used by the authors to further their own ends actually work against each other to deconstruct and undermine the message they wish to present. Finally, it will consider some of the implications for teaching and research, particularly into English as a lingua franca (ELF). Examples will be taken from a range of 'Dearly beloved' emails as well as the two reproduced in full above. 


\section{Persuasive strategies}

\section{The hook}

The main objective of the 'Dearly beloved' email is to lure the recipient into parting with bank account details or money for legal or processing fees with the promise of a large amount of 'locked' money. Spammers use three main tactics to 'hook' their prey.

a Appealing to instincts of greed

The most fundamental appeal of these spam emails is to greed. They make systematic use of expressions like the following:

- I seek your assistance for investing huge amount of money on my behalf.

- I want to compensate you and show my gratitude to you with the sum of \$1.2Million. I have left an international certified bank draft for you worth about \$1.2Million, cashable anywhere in the world.

- Firstly you can choose to have a certain percentage of the money for nominating your account for this transaction. Or you can go into partnership with me for the proper profitable investment of the money in your country.

b Creating a sense of drama and urgency

The money promised to the recipient has usually become available as the result of dramatic circumstances: war, murder, terrorist attack, plane crash, or some other catastrophe.

- I want to release the money to you as the nearest person to my late client who died a long with his supposed next of kin in the event of terrorist attack on 11th September 2001 World Trade Centre.

- My father was a revolutionary executed by the Iraqi dictator, Saddam Hussein.

This drama and urgency is intensified by the recounting of circumstances which demand immediate action or the huge amounts of money will be lost:

- ... according to my doctors they have advised me that I may not live for the next two months, this is because the cancer stage has gotten to a very bad stage.

- We are totally frustrated that our whole mind for now lies on our survival which is securing this money out from this place.

c Appealing to the recipient's pity and enlisting sympathy

The spammers rely on the presumed universality of emotions as a means of creating a bond of sympathy. In this way emotion is deliberately used as a persuasive agency.

- Recently, my Doctor told me that I have a limited or numbered days on earth and that my life span will not exceed 150 days.

- WAITING FOR DEATH. Two years of battle with cancer of the breast, I am dying. In tears and great pain...

Also notable is the writer's use of the expression, WAITING FOR DEATH, written in block letters, and consequently screaming for attention.

\section{Creating rapport}

Spammers make their emails as personalized as possible to mask the fact that this is communication between strangers. 
a Assuming intimacy

A typical letter from South Asia, the Far East, or Africa will have an extremely deferential lexical spread based on the politeness hierarchy of the L1 and abundant use of blessings in the opening and concluding paragraphs. (Kachru 1992: 338)

The Dearly beloved spam makes consistent use of deferential greetings:

- Happiness keeps you sweet, trials keeps you strong, sorrows keeps you human, failures keeps you humble, success keeps you blooming, and only God keeps you going! You are so special!

- Can you honestly help me as your Sister?

In addition to the deferential greetings, these emails are notable for the intimacy with which they address the recipient, as if a prior relationship exists.

b Employing flattery

The author frequently refers to the recipient in flattering terms, most notably as a trustworthy and honest person:

- Due to your effort, sincerity, courage and trust worthiness you showed during the course of the transaction I want to compensate you and show my gratitude to you with the sum of $\$ 1.2 \mathrm{Million}$.

These flattering references imply that the recipient has been singled out, not by chance, but because of his/her exceptional personal qualities, thus that she/he deserves to be rewarded.

\section{Reassurance}

The hook is not enough on its own or reinforced by supposed intimacy and flattery. It must be backed up by various strategies designed to reassure the recipient and create trust and confidence.

a Reliability and straightforwardness: the use of deglamorized names Spammers use unglamorous or rather ordinary names. In fact, one has to appreciate the spammer's ingenuity in creating fake profiles; they always seem to come up with names which seem deceptively simple. Simple because one does not expect a Jacob, George, or Richard to be associated with any kind of a scam, rather these are the sorts of names which could potentially belong to a friend. The names are mostly traditional English names, such as John, Paul, William, Charles, etc., suggesting reliability and a certain conservatism. Other more unusual names often have benign associations_-Carus: care/ dear; Earnestina: honesty, earnestness; Bona: good.

b Establishing credentials: creating an identity of repute

Spammers strive to create an identity which suits the image of a person of substance and immense personal worth often in the finance or banking world and frequently with connections in high places.

- First, let me start by introducing myself as Mr. Carus Adams, a staff in the Private Clients Section of a well-known bank, here in London, England

- My name is Ernestina ___ married to the former minister of finance here in Philippine who was assassinated for been working with Joseph E, the ex president of Philippine.

c Building trust and confidence

The spammer takes great pains to reassure the reader that the proposed arrangement is above board and risk free. Some expressions which seek the trust of the readers are:

- There is no risk involved as every arrangement has been perfected. 
- I want you to understand that this business is $100 \%$ risk free.

However, trust is a two way process and it is interesting that an even larger part of the spammer's efforts are directed at making recipients conscious of their duties and of the trust placed in them by the spammer. This is a clever strategy, as it puts the onus on the recipients to prove themselves worthy of the spammer's trust rather than the other way round.

- I hope you will not expose or betray the trust and confident that I am about to repose on you for the mutual benefit of our both families.

d Capitalizing on global knowledge

A strategy spammers employ is to invoke the names of world-famous events, leaders, and notorious dictators, perhaps in the belief that sourcing the reasons for the 'locked money' problem in famous world events will somehow lend credibility to their appeal. The 'credibility' lies partly in the factual nature of the events: everyone knows that they happened and this somehow grounds the story in reality, but it may also work by appealing to a shared background as global citizens in a similar way to the universal emotions ploy.

- This land problem came when Zimbabwean President MR.ROBERT MUGABE introduced a new Land Act which wholly affected the rich white farmers and some few black farmers. This resulted to the killing and mob action by Zimbabwean war veterans and some lunatics in the society.

e Invoking religious sentiments

Another strategy for providing reassurance is the incessant use of language strewn with religious sentiments.

- I believe when God gives me a second life to be on this earth, I will live very differently.

- It is often said that blessed is the hand that gives.

Religious messages are sometimes allied to the promise of using the money to perform good works:

- I want this fund to be used in liberation work Activities like, help to Pastors families, Orphanages, less privileged in the society and Christian schools, poor people in your amidst and up keeping of the Churches and for propagating the word of God and to endeavour that the house of God is maintained.

Despite - or more probably because of - the use of a number of complex and powerful persuasive strategies, the emails ultimately fail in their persuasive intent since they undermine themselves in several ways. This self-undermining is partly due to cross-cultural glitches, partly to the sheer number of strategies used and their incongruous combination, which results in inconsistency of tone and conflict of register, manifesting itself in unintentionally comic ways.

\section{Cross-cultural glitches}

Here, the message of the spammer may not lead to uptake on the part of the recipient in quite the way the spammer intended due to differences across cultures. One example of a potential cross-cultural glitch is the spammer's use of 'ornamentation, deferential style' (Kachru op.cit.: 338) in greetings. When this is coupled with the familiarity and intimacy 
with which the spammer addresses the unknown recipient, this may well not transfer smoothly across cultures and be felt as inappropriate or intrusive by the recipient.

\section{Cross-cultural glitch or universal conmanship?}

Another example of a potential cross-cultural glitch is the 'solidarity through universal emotions' strategy. Although Darwin proposed that 'emotional expressions derive from the evolutionary past of our species' (Oakley 2004: x) and are thus cross-culturally universal, social psychologists are divided about how far emotions are universal across cultures. Wierzbicka (1999: 34), for example, finds that, 'human emotions vary a great deal across language and cultures, but also share a great deal' while Ekman and Friesen (1997:331) find that there is 'cultural variability with respect to 1 )the kinds of stimulus that elicit certain emotions and 2) the rules governing the appropriateness of expressing our emotions in public'. Anna Wierzbicka adds that, 'there is a certain unconscious ideology written into the English word emotional, an ideology which assumes that showing feelings over which one has no control is a departure from "normal"' behaviour. The word has pejorative overtones' (Wierzbicka: op.cit.: 19). Given these attitudes, the description of highly emotional or dramatic situations in highly charged language in an email to a stranger may have a very different effect on the recipient from that intended by the sender! However, further research is needed to determine whether the over-charged emotion which is intended to gain sympathy, but which actually alienates, is indeed a cross-cultural glitch or part of the repertoire of (inexpert) conmen worldwide.

\section{Incongruous and unintentionally funny juxtapositions}

Incongruous juxtaposition can be seen as the basis of all comedy-an idea first suggested by Immanual Kant in his famous definition of comedy in The Critique of Pure Reason, as the 'sudden transformation of a strained expectation into nothing' and elaborated on by theorists such as Schaeffer. 'Comedy results from an incongruity perceived in a ludicrous context' (Schaeffer 1981: 17) and 'Incongruity is a perceived juxtaposition of apparently unrelated ideas or things’ (ibid.: 8-9).

The ‘Dearly beloved’ spam email is peppered with such ludicrous incongruities!

a Highly emotive images contrast with unnecessarily precise factual information

- My husband was a businessman before the cold hand of death took him away on the 3rd of December, 2005 at about 2:00am.

b Formal and elevated language contrasts with a sudden descent into colloquial language

- you should not entertain any fear because i am sure of the success as an insider in the bank ok.

c Over elaborate linguistic complexity contrasts with linguistic inaccuracies

- The said deceased was one of the best clients in my Firm so therefore, I don't want the money to go into Bank Treasury as an abandoned fund according to the bank protocols guiding inheritance fund here because I'm the only person in position now to declare whom to claim the money.

d Business practicalities contrast with human drama

- Do kindly go through this letter because it means me and my sister's life, entire future. 
e Very formal deferential politeness markers contrast with informal greetings

- How are you today? Hope all is well with you and your family? I hope this mail meets you in a perfect condition.

\section{Conclusion}

David Graddol suggests that 'understanding how non-native speakers use English among themselves has now become a serious research area' (Graddol 2006: 87). This article suggests that a close reading of spam emails can provide illuminating insights into the position of ELF and global language, reaffirming David Crystal's assertion that, 'a totally uniform, regionally neutral, and unarguably prestigious variety does not yet exist worldwide' (Crystal 1995: 111). Indeed it raises the question that, even if syntactical and phonological simplification become accepted as standardized across Englishes in ELF, as sociolinguists such as Jenkins and Seidlhofer suggest, register and cross-cultural awareness could prove far harder barriers to cross in a journey to that hypothetical 'regionally neutral totally uniform variety’.

\section{References}

Crystal, D. 1995. The Cambridge Encyclopedia of the English Language. Cambridge: Cambridge University Press.

Ekman, P. and W. V. Friesen. 1997. 'Constants across cultures in the face and emotion' in M. Hewstone, S. R. Manstead and W. Stroebe (eds.). The Blackwell Reader in Social Psychology. Oxford: Blackwell.

Graddol, D. 2006. English Next. London: British Council.

Kachru, B. (ed.). 1992. The Other Tongue: English Across Cultures. Oxford: Oxford University Press.

Oakley, K. 2004. Emotions: A Brief History.Oxford: Blackwell.

Schaeffer, N. 1981. The Art of Laughter. New York: Columbia.

Wierzbicka, A. 1999. Emotions Across Languages and Cultures: Diversity and Universals. Cambridge: Cambridge University Press. 